\title{
Educação Especial nas Escolas Indígenas: Análise do Censo Escolar de 2007-2010
}

\author{
Michele Aparecida de Sä* \\ Fabiana Cia**
}

\section{Resumo}

Na política educacional brasileira é observado que a interface da Educação Especial com a Educação Indígena está em construção. Portanto, investigar como essa interface vem sendo implementada no contexto das escolas indígenas é de suma relevância. Assim, este trabalho teve por objetivo geral analisar a interface entre a Educação Especial na Educação Escolar Indígena no Brasil, por meio de dados de matrículas do censo escolar entre os anos de 2007 - 2010. Os objetivos específicos resultaram em caracterizar: (a) o número de matrículas de alunos indígenas com deficiência nas escolas indígenas; (b) os tipos de deficiências encontradas na população indígena; (c) as modalidades de ensino em que os alunos indígenas com deficiência estão matriculados e (d) verificar se os alunos indígenas com deficiência recebem atendimento educacional especializado. Os dados foram coletados por meio dos Microdados do Censo Escolar da Educação Básica, disponibilizados pelo Instituto Nacional de Estudos e Pesquisas Educacionais Anísio Teixeira (INEP), referentes aos anos de 2007, 2008, 2009 e 2010. Este estudo constatou que houve um crescimento significativo do número de alunos indígenas com deficiência matriculados nas escolas indígenas do Brasil. No que se refere ao atendimento educacional especializado, destaca-se que houve aumento do número de matrículas de alunos com deficiência nas escolas indígenas sem qualquer tipo de atendimento.

Palavras-chave: Educação Especial; Educação Escolar Indígena; Censo Escolar.

\footnotetext{
* Doutoranda em Educação Especial pela Universidade Federal de São Carlos (UFSCar), São Carlos, São Paulo, Brasil.

** Professora Doutora da Universidade Federal de São Carlos (UFSCar), São Carlos, São Paulo, Brasil.
} 


\section{Special Education on Indigenous Schools: analysis of the school census of 2007-2010}

\section{Abstract}

On Brazilian educational policy it is noted that the interface between Special Education with Indigenous Education is being built. Thus, to investigate how this interface is being implemented in the context of Indigenous Schools is of high relevance. So, this paper has as a general objective to analyze the interface between Special Education and Indigenous Education in Brazil, using school enrollment data of 2007-2010's school census. The specific objectives resulted in characterizing: (a) the amount of enrollments made by indigenous students with disabilities on indigenous schools; (b) the kinds of disabilities found on indigenous population; (c) the type of education indigenous students with disabilities are enrolled in; and (d) to verify if the indigenous students with disabilities receive specialized educational services. Data were collected through "Microdados do Censo Escolar da Educação Básica", provided by the Instituto Nacional de Estudos e Pesquisas Educacionais Anísio Teixeira (INEP), referred to the years of 2007, 2008, 2009 and 2010. This study found out there was a significant increase of the number of indigenous students with disabilities enrolled on indigenous schools in Brazil. Regarding specialized educational services, it is emphasized that there was an increase of the number of students with disabilities on indigenous schools, without any kind of special care.

Keywords: Special Education; Indigenous School Education; School Census.

\section{Introdução}

A proposta de educação para alunos com deficiência tem sido um tema presente nas discussōes atuais. No que se refere aos aspectos políticos, no decorrer da história, diversas legislações têm norteado a Educação Especial brasileira. Com a proposta de integração das pessoas com deficiência, na década de 1960, a Lei de Diretrizes e Bases da Educaçáo Nacional (Lei n. 4.024) reafirma o direito à educaçáo dessas pessoas, indica em seu Artigo 88 que, para integrá-las na comunidade, sua educação deverá, dentro do possível, enquadrar-se no sistema geral de educação. Nesta perspectiva, a Lei n. 5.692/71 referente Diretrizes e Bases para ensino de $1^{\circ}$ e $2^{\circ}$ graus, no Artigo $9^{\circ}$, veio assegurar tratamento especial aos alunos que apresentem deficiências físicas ou mentais (MAZZOTTA, 2005).

No final da década de 1980, com a promulgação da Constituição Federal de 1988 (C.F/1988), observa-se ampliaçáo significativa de leis e políticas referente à educação das pessoas com deficiência. Destaca-se o direito público subjetivo à educação de todos, inclusive daqueles com algum tipo de deficiência, preferencialmente, na rede regular de ensino. Estabelece como princípios para o ensino: a igualdade de condiçóes de acesso e permanência na escola; o dever do Estado de garantir o acesso aos níveis mais elevados do ensino; a oferta do Atendimento Educacional Especializado (Art. 205, 206, 208). 
A partir da década de 1990, as propostas políticas para a Educação Especial procuraram atender as indicaçóes de movimentos internacionais que visavam uma perspectiva inclusiva. Assim, as políticas educacionais brasileiras incorporaram as orientações internacionais tratadas na Conferência Mundial de Educação para Todos (JOMTIEN, 1990) e na Declaração de Salamanca (1994).

No que diz respeito à Declaração Mundial sobre Educação para Todos (JOMTIEN, 1990), esta ressalta a educação como direito social e a necessidade dos Estados partes tomarem medidas para a garantia da igualdade de oportunidades às minorias sociais, linguísticas e às pessoas com deficiência, quanto ao acesso e à promoção da aprendizagem nos diferentes níveis de ensino.

A Declaração de Salamanca (ESPANHA, 1994) trouxe transformaçôes significativas referente aos objetivos da Educação Especial, uma vez que recomenda a inclusão no ensino regular de todas as crianças com deficiência. Preconiza que as escolas inclusivas devam reconhecer e responder às necessidades específicas de seus alunos e aponta para a necessidade de existir uma continuidade de serviços e apoio proporcional às necessidades especiais encontradas dentro da escola regular.

Observa-se que a Educação Especial, que por muito tempo se constituiu paralela ao sistema de ensino regular, está sendo obrigada a redimensionar o seu papel, antes restrito ao atendimento direto dos alunos com deficiência, para atuar, prioritariamente, como suporte à escola regular no recebimento deste alunado (PLETSCH; FONTES; GLAT, 2006, p. 03).

Nesta perspectiva, nas políticas educacionais brasileiras, a Educação Especial passa a ser identificada como uma modalidade de educação a ser ofertada, preferencialmente, na rede regular de ensino, a partir da educação infantil.

Assim, a Lei de Diretrizes e Bases da Educação Nacional n. 9.394/96 (LDB/1996) determina que o acesso à educação das pessoas com deficiência deve iniciar na educação infantil e ir até o ensino superior. Traz um novo conceito de Educação Especial, definida como modalidade transversal que perpassa todos os níveis de ensino. Preconiza que os sistemas de ensino deverão assegurar aos alunos com deficiência "[...] currículos, métodos, técnicas, recursos educativos e organização específica para atender às suas necessidades" (Art. 58 e 59).

Na Política Nacional de Educação Especial na Perspectiva da Educação Inclusiva (BRASIL, 2008), a Educação Especial se constitui como uma modalidade de ensino que perpassa todos os níveis, etapas e modalidades, realiza o Atendimento Educacional Especializado (AEE), identifica as necessidades educacionais especiais, disponibiliza os serviços e recursos próprios desse atendimento e orienta os alunos e seus professores quanto a sua utilização nas salas comuns do ensino regular.

Nessa política, cabe à Educação Especial orientar os sistemas de ensino para promover respostas às necessidades educacionais especiais, garantindo: transversalidade da educação especial e atendimento educacional especializado em todos os níveis de ensino; continuidade a níveis mais elevados de ensino; formação de professores 
para o atendimento educacional especializado e demais profissionais da educaçáo para a inclusáo escolar; participaçáo da família e da comunidade; acessibilidade na comunicação e informação, urbanística e arquitetônica, nos mobiliários e equipamentos; articulação intersetorial na implementação das políticas públicas.

Apesar da Constituição Federal/1988 e LDB/1996 representarem avanços quanto à educação das pessoas com deficiência, esses documentos não contemplam açóes específicas voltadas à Educação Especial para a população indígena com deficiência.

A Política Nacional de Educação Especial na Perspectiva da Educação Inclusiva (2008) trouxe avanços nesse sentido, pois foi o primeiro documento oficial que tratou especificamente do direito à Educação Especial para a população indígena com deficiência. Este documento assegura que os recursos, serviços e o Atendimento Educacional Especializado estejam nos projetos políticos pedagógicos das escolas indígenas, os quais devem ser construídos com base nas diferenças socioculturais dessa população.

A interface entre a Educação Especial e a Educação Indígena também foi contemplada na versão final do documento da Conferência Nacional de Educação (CONAE). No eixo VI, destinado a "Justiça Social, Educação e Trabalho: Inclusão, Diversidade e Igualdade" é mencionado a necessidade de se construir a interface da Educação Especial com a Educação Escolar Indígena. No item destinado a Educação Indígena, o documento propóe que as políticas deverão "Estimular a interface da educação especial na educação indígena, assegurando que os recursos, serviços e AEE estejam presentes nos projetos pedagógicos, construídos com base nas diferenças socioculturais desses grupos" (CONAE, 2010, p. 141).

No Plano Nacional de Educação (2011-2020), em tramitação no Congresso Nacional, em sua Meta 4, destinada a "Universalizar para a população de 4 a 17 anos, o atendimento escolar aos estudantes com deficiência na rede regular de ensino", no item 4.2 é apontando como meta "Implantar salas de recursos multifuncionais e fomentar a formação continuada de professores para o atendimento educacional especializado complementar, nas escolas urbanas e rurais" (ressalta-se que as Escolas Indígenas situam-se na zona rural).

Nos documentos citados, verifica-se que a interface da Educação Especial com a Educação Escolar Indígena está em construção na política educacional. Portanto, cabe investigar como essa interface vem sendo implementada no contexto das escolas indígenas brasileiras, pois, os poucos estudos que se têm na área (SÁ, 2011; SOUZA, 2011) apontam lacunas existentes entre a legislação e as políticas implementadas, principalmente no que se refere ao acesso e permanência de alunos indígenas com deficiência em escolas indígenas.

Ao considerar que o acesso a educação de pessoas com deficiência no ensino regular ainda se constitui como um grande desafio para a escola brasileira, torna-se necessário investigar, por meio indicadores educacionais, (indicadores educacionais da educaçáo sáo construídos desde a década de 1980, a partir da base de dados dos 
Censos Escolares coletados anualmente pelo INEP), se os alunos indígenas com deficiência estão frequentando a escola indígena de sua comunidade.

Neste contexto, surgiram as seguintes questôes: - Houve evolução do número de matrículas de alunos indígenas com deficiência após a regulamentação de políticas que enfatizam o direito à educação e ao atendimento educacional especializado? - Os alunos indígenas com deficiência matriculados em escolas indígenas recebem atendimento educacional especializado?

Assim, o objetivo deste estudo resultou em analisar a interface entre a Educação Especial na Educação Escolar Indígena no Brasil, por meio de dados de matrículas do censo escolar entre os anos de 2007 - 2010. Os objetivos específicos resultaram em verificar: (a) o número de matrículas de alunos indígenas com deficiência nas escolas indígenas; (b) os tipos de deficiências encontradas na população indígena; (c) as modalidades de ensino em que os alunos indígenas com deficiência estão matriculados e (d) o número de alunos indígenas com deficiência que receberam atendimento educacional especializado

Observa-se que este trabalho pretendeu demonstrar, por meio do número de matrículas divulgadas pelo censo escolar, como está ocorrendo a interface entre a Educação Especial nas escolas indígenas do Brasil. Cabe destacar que estudos focados no censo escolar são relevantes, pois, segundo Gatti (2004), existem problemas educacionais que, para serem contextualizados, necessitam ser quantificados e muitas informaçốes estấo disponíveis nas bases de dados existentes e precisam ser investigadas.

\section{Método}

O estudo se desenvolveu por meio de abordagem quantitativa, a qual, segundo Minayo e Sanches (1993), tem como campo de práticas e objetivos trazer à luz dados, indicadores e tendências observáveis. Os autores apontam que deve ser utilizada para abarcar, do ponto de vista social, grandes aglomerados de dados, de conjuntos demográficos, por exemplo, classificando-os e tornando-os inteligíveis através de variáveis.

Para este estudo, os dados foram coletados nos Microdados da Educação Básica do Instituto Nacional de Estudos e Pesquisas Educacionais Anísio Teixeira (INEP). Cabe esclarecer que os microdados fazem parte da base de dados dos censos escolares, os quais se configuram como um levantamento anual de dados estatístico-educacionais de âmbito nacional, coordenado pelo INEP (INEP, 2009).

Os dados coletados nos Microdados do Censo Escolar da Educação Básica são referentes aos anos de 2007, 2008, 2009 e 2010. A escolha por esse recorte temporal justifica-se pelo fato de que até 2006 a unidade básica do censo escolar era a escola, a partir de 2007, o censo adota o aluno como unidade básica de coleta, incluindo, além dos dados gerais sobre a escola, informaçóes específicas sobre cada aluno, cada professor regente e cada turma. Observa-se que esta nova forma de coleta de dados possibilita recolher um número maior de informaçóes de cada aluno. 
Assim, neste banco de dados, coletou-se, por meio do programa SPSS versão 17.0, os dados referentes às matrículas de alunos indígenas com deficiência matriculados em diferentes níveis, etapas e modalidades de ensino em escolas indígenas do Brasil. Em virtude da grande diversidade de variáveis, para este estudo escolheu-se as seguintes: matrículas de alunos com deficiência na educação indígena por modalidade de ensino, tipos de deficiências, atendimento educacional especializado. Destacase que foram coletados dados referentes aos seguintes tipos deficiências: deficiência visual (B.V e cego), deficiência auditiva (surdez e D.A), surdocegueira, deficiência física, deficiência intelectual, deficiência múltipla.

\section{Resultados e Discussão}

Apesar dos dados censitários serem criticados e considerados limitados, não se pode desconsiderar que eles são determinantes na elaboração de políticas públicas educacionais, inclusive para as pessoas com deficiência. Apesar de suas limitaçóes, esses dados podem revelar as alteraçóes quantitativas referentes ao acesso no sistema educacional de alunos indígenas com deficiência, que estão matriculados em estabelecimentos que oferecem a educação escolar indígena.

Tomando como referência os Microdados da Educação Básica, coletados pelo INEP, no período de 2007 a 2010, foram analisados os dados de matrículas de alunos indígenas com deficiência que estáo matriculados na educaçáo escolar indígena segundo: modalidade de ensino (Ensino Regular, Educação Especial, EJA - neste estudo as modalidades serão consideradas conforme são separadas pelos microdados); tipo de deficiência e atendimento educacional especializado.

Para análise dos dados de matrículas dos alunos indígenas com deficiência, considera-se necessário apresentar os dados gerais de matrículas na educação escolar indígena. A Tabela 1 apresenta os dados gerais referentes ao número de matrículas na educaçáo escolar indígena no Brasil, por modalidade de ensino.

Tabela 1. Número de matrículas na educaçáo escolar indígena por modalidade de ensino

\begin{tabular}{|c|c|c|c|c|}
\hline \multirow[t]{2}{*}{ ANO } & \multirow{2}{*}{$\begin{array}{c}\text { Total Geral de } \\
\text { matrículas na } \\
\text { Educaçáo básica } \\
\text { Brasil }\end{array}$} & \multirow{2}{*}{$\begin{array}{l}\text { Total geral de } \\
\text { matrículas na } \\
\text { Educaçáo escolar } \\
\text { indígena Brasil }\end{array}$} & \multicolumn{2}{|c|}{$\begin{array}{l}\text { Modalidade de en- } \\
\text { sino na educaçáo } \\
\text { escolar indígena }\end{array}$} \\
\hline & & & $\begin{array}{l}\text { Ensino } \\
\text { Regular }\end{array}$ & EJA \\
\hline 2007 & 52179530 & 101.342 & 95.123 & 6.219 \\
\hline 2008 & 52321667 & 198.591 & 185.466 & 13.125 \\
\hline 2009 & 52580452 & 225.629 & 203.972 & 21.657 \\
\hline 2010 & 51549889 & 245.702 & 225.676 & 20.026 \\
\hline
\end{tabular}

Fonte: MEC/INEP. Censo Escolar da Educação Básica: microdados, 2007, 2008, 2009 e 2010. 
Ao analisar os dados da Tabela 1, verifica-se que, no Brasil, em 2010, o número de matrículas de alunos na educação escolar indígena representava $0,48 \%$ do total de matrículas da educação básica. Com relação ao número de matrículas na educação escolar indígena por modalidade de ensino, observa-se que, no decorrer do período estudado, houve aumento contínuo do número de matrículas, com exceção apenas no ano de 2010, na EJA.

A Tabela 2 apresenta os dados de matrículas de alunos indígenas com deficiência por modalidade de ensino no Brasil.

Tabela 2. Número de matrículas de alunos indígenas com deficiência por modalidade de ensino

\begin{tabular}{lcccc}
\hline ANO & $\begin{array}{c}\text { Ensino Re- } \\
\text { gular }\end{array}$ & $\begin{array}{c}\text { Educaçáo } \\
\text { Especial }\end{array}$ & $\begin{array}{c}\text { Educaçáo de } \\
\text { jovens e adultos } \\
\text { EJA }\end{array}$ & TOTAL \\
$\mathbf{2 0 0 7}$ & 280 & 137 & 172 & $\mathbf{5 8 9}$ \\
$\mathbf{2 0 0 8}$ & 361 & 213 & 73 & $\mathbf{6 4 7}$ \\
$\mathbf{2 0 0 9}$ & 453 & 16 & 42 & $\mathbf{5 1 1}$ \\
$\mathbf{2 0 1 0}$ & 736 & 53 & 72 & $\mathbf{8 6 1}$ \\
\hline
\end{tabular}

Fonte: MEC/INEP. Censo Escolar da Educaçâo Básica: microdados, 2007, 2008, 2009 e 2010.

De acordo com os dados apresentados na Tabela 2, houve, no ensino regular, um aumento expressivo do número de matrículas de alunos indígenas com deficiência nessa modalidade de ensino, o cotejamento dos dados de 2010, com o ano base de 2007 , mostra um aumento de $262,9 \%$ desse alunado no ensino regular. Este aumento pode ter ocorrido devido à criação de políticas públicas inclusivas que recomendam a entrada de alunos com deficiência nas escolas regulares, este é o caso da Política Nacional de Educação Especial na Perspectiva da Educação Inclusiva (BRASIL, 2008), a qual enfatiza que os alunos com deficiência, transtornos globais do desenvolvimento e altas habilidades devem ter acesso, participação e aprendam nas escolas regulares.

Outro fato observado é que, quando se compara os dados da modalidade Educação Especial entre os anos de 2007 e 2010, verifica-se uma diminuição de 61,3\% do número de matrículas na Educação Especial. Vale destacar que tal redução pode tanto indicar migração para as outras modalidades de ensino ou escolas que não oferecem educação escolar indígena quanto evasão escolar. Os dados coletados neste estudo náo permitem este tipo de análise, assim remetem à necessidade de se realizar outras investigaçóes.

Com relação à modalidade de ensino EJA, no período estudado, observou-se que houve uma diminuição de $58,1 \%$ do número de matrículas de alunos indígenas com deficiência nessa modalidade. Destaca-se que esse resultado vai à contrapartida aos achados de Meletti e Bueno (2010). O estudo realizado pelos autores, sobre a situação das matrículas do alunado da Educaçáo Especial no Brasil, aponta o crescimento do número de matrículas de alunos com deficiência na EJA. 
Para ilustrar melhor como estão distribuídos os alunos indígenas com deficiência por modalidade de ensino, na Tabela 3, apresentam-se dados de matrículas de alunos por tipo de deficiência e modalidade de ensino.

Tabela 3. Número de matrículas na educação escolar indígena por tipo de deficiência e modalidade de ensino.

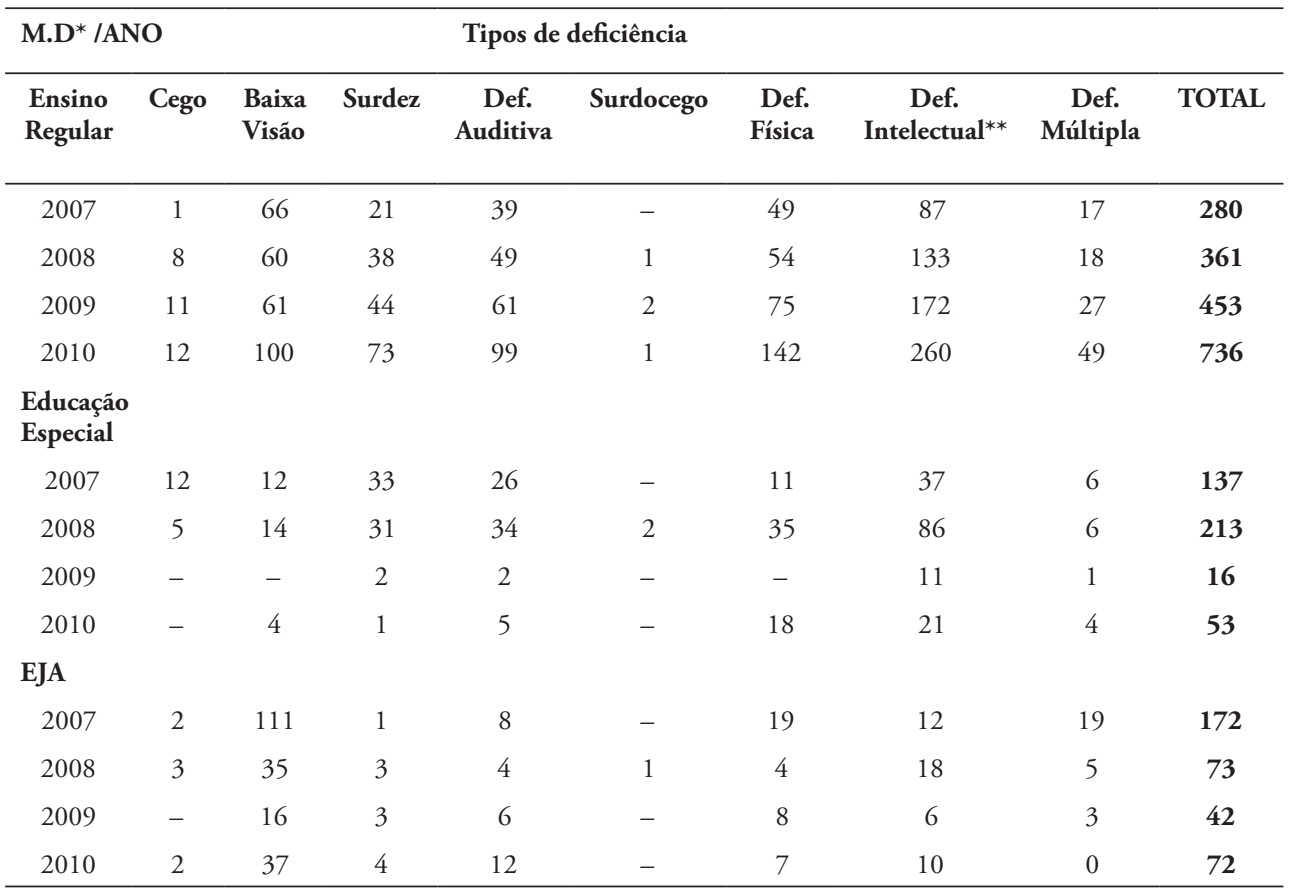

Fonte: MEC/INEP. Censo Escolar da Educação Básica: microdados, 2007, 2008, 2009 e 2010. Obs. *Modalidade de Ensino. O termo deficiência intelectual foi substituído pelo termo deficiência mental.

Os dados indicam que, no ano de 2007, existiam no ensino regular 280 matrículas de alunos indígenas que possuíam alguma das deficiências selecionadas. A maior incidência neste ano foi a de alunos com deficiência intelectual, com 31,1\% dos casos, seguida por alunos com baixa visão, 23,6\%, alunos com deficiência física, 17,5\%. Nos anos subsequentes, teve-se um aumento gradativo do número de matrículas de alunos indígenas com deficiência no ensino regular. No ano de 2010, verificou-se que, das 736 matrículas, a maior incidência foi novamente da deficiência intelectual, com $35,3 \%$ dos casos, seguida por deficiência física, 19,3\%, e baixa visão, 13,6\%. Ressalta-se que, em todos os anos do período analisado, a maior incidência de matrículas é de alunos com deficiência intelectual.

No caso dos alunos indígenas com deficiência intelectual, chama a atenção a incidência e o aumento das matrículas ao longo do período analisado. Quando cotejados os dados deste estudo com os achados de Meletti e Bueno (2010), verifica-se que ambos os estudos apontam um crescimento significativo do número de 
matrículas de alunos com deficiência intelectual no ensino regular. Sabe-se que existe uma dificuldade em identificar e diagnosticar alunos com tal deficiência, que, muitas vezes, acarreta nos alunos com dificuldades de aprendizagem, ou mesmo problemas de comportamento, serem identificados com deficiência intelectual (VELTRONE, 2011).

Com relação aos sistemas segregados de ensino, neste estudo representado pela modalidade de educaçáo especial, a qual é entendida pelo censo escolar como escolas especiais ou classes especiais, verificou-se que, no ano de 2007, existiam 137 matrículas de alunos indígenas com deficiência. Destaca-se que a maior incidência neste ano foi da deficiência intelectual, com $27,0 \%$ dos casos, seguida pela surdez, $24,1 \%$ e deficiência auditiva, com $18,9 \%$ dos casos. No ano de 2010, existiam 53 matrículas nessa modalidade de ensino e mais uma vez a incidência foi maior na deficiência intelectual, com 39,7\% dos casos, seguida pela deficiência física, 33,9\%, e deficiência auditiva, 9,4\%.

Cabe salientar que as matrículas na educação especial sofreram oscilação no decorrer do período estudado. Houve um aumento expressivo no ano de 2008, com 213 matrículas, no ano seguinte (2009) essas matrículas tiveram um decréscimo significativo, caíram para 16 e aumentaram novamente no ano de 2010 para 53 matrículas. Essa oscilação durante o período analisado pode ter ocorrido em virtude da elaboração e implementação de políticas públicas que recomendam a entrada de alunos com deficiência no sistema regular de ensino.

No caso da modalidade de ensino EJA, os dados indicam que, no ano de 2007, existiam 172 matrículas de alunos indígenas com deficiência. Destaca-se que a maior incidência neste ano foi de alunos com baixa visão, a qual correspondeu a $64,5 \%$ das matrículas, seguida pela deficiência física, 11,0\%, e deficiência múltipla, 11,0\%. Nos anos seguintes teve-se um decréscimo do número de matrículas nos anos de 2008 (73 matrículas) e 2009 ( 42 matrículas) e aumento em 2010 (72 matrículas). Enfatiza-se que a deficiência que teve maior incidência, no período analisado, foi à baixa visão, no ano base de 2007 existiam 111 casos, em 2010 esses dados diminuíram para 37, porém essa deficiência continuou a ter a maior incidência.

Observou-se, neste estudo, que os dados anteriores revelaram a existência de alunos indígenas com deficiência matriculados nas diferentes modalidades de ensino. No entanto, na Tabela 4, serão apresentados dados referentes ao atendimento educacional especializado, ou seja, será demonstrado se os alunos com deficiência, que estavam matriculados nas escolas indígenas do Brasil, recebiam algum tipo de atendimento educacional especializado. 
Tabela 4. Número de alunos na educação escolar indígena que recebem atendimento educacional especializado.

\begin{tabular}{cccc}
\hline $\begin{array}{c}\text { Modalidade de } \\
\text { Ensino Ano }\end{array}$ & $\begin{array}{c}\text { Matrículas } \\
\text { de alunos } \\
\text { que possuem } \\
\text { deficiência }\end{array}$ & $\begin{array}{c}\text { NÁO recebe } \\
\text { atendimento } \\
\text { educacional } \\
\text { especializado }\end{array}$ & $\begin{array}{c}\text { Recebe } \\
\text { atendimento } \\
\text { educacional } \\
\text { especializado }\end{array}$ \\
\hline $\begin{array}{c}\text { Ensino Regular } \\
\mathbf{2 0 0 6}\end{array}$ & 280 & 212 & 68 \\
$\mathbf{2 0 0 7}$ & 361 & 258 & 103 \\
$\mathbf{2 0 0 8}$ & 453 & 387 & 66 \\
$\mathbf{2 0 0 9}$ & 736 & 736 & 0 \\
EJA & & & \\
$\mathbf{2 0 0 6}$ & 172 & 96 & 76 \\
$\mathbf{2 0 0 7}$ & 73 & 37 & 36 \\
$\mathbf{2 0 0 8}$ & 42 & 42 & 0 \\
$\mathbf{2 0 0 9}$ & 72 & 72 & 0 \\
\hline
\end{tabular}

Fonte: MEC/INEP. Censo Escolar da Educação Básica: microdados, 2007, 2008, 2009 e 2010.

Ao analisar os dados da Tabela 4, é verificado que nem todos os alunos com deficiência recebiam atendimento educacional especializado. No ensino regular, podese perceber que houve um aumento significativo do número de matrículas de alunos com deficiência no período estudado, porém, se compararmos o ano de 2010 com o ano base de 2007, verifica-se um decréscimo significativo do número de alunos que recebiam atendimento educacional especializado, ou seja, em 2007, 68 alunos recebiam atendimento, no entanto, em 2010 nenhum aluno recebeu.

$\mathrm{Na}$ EJA verifica-se também a existência de alunos indígenas com deficiência que não receberam atendimento educacional especializado. Os dados revelam que existiu atendimento apenas em 2007 e 2008, nos anos subsequentes, nenhum aluno com deficiência recebeu atendimento.

Cabe destacar que o atendimento educacional especializado é um direito assegurado em diversas legislaçóes e documentos. A CF/1988, garante à oferta do Atendimento Educacional Especializado as pessoas com deficiência preferencial no ensino regular (Art. 208). A LDB/1996 também assegura o atendimento educacional às pessoas com deficiência.

Neste contexto, a Política Nacional de Educação Especial na Perspectiva da Educação Inclusiva (BRASIL, 2008) atribui responsabilidade ao poder público quanto a efetivação do Atendimento Educacional Especializado. Esta política também assegura que os recursos, serviços e o Atendimento Educacional Especializado estejam nos projetos políticos pedagógicos das escolas indígenas, os quais devem ser construídos com base na diferença socioculturais dessa população.

Atualmente, há uma movimentação do governo para a implantação de salas de recursos multifuncionais para ofertar o atendimento educacional especializado aos 
alunos com deficiência, porém, neste estudo, constatou-se que essas salas não estão chegando às escolas indígenas.

\section{Considerações finais}

Este estudo analisou como está ocorrendo a interface entre a Educação Especial na Educação Escolar Indígena no Brasil, por meio de dados de matrículas do censo escolar. Diante da análise dos dados, cabe estabelecer algumas reflexóes.

Com relação às matrículas, nos quatro anos estudados, constatou-se que houve um crescimento significativo do número de alunos indígenas com deficiência matriculados nas escolas indígenas do Brasil. Por outro lado, embora tenha havido este aumento dos alunos com deficiência incluídos no ensino regular, este acréscimo não parece refletir em açóes ou nas políticas públicas educacionais.

No que se refere ao atendimento educacional especializado, destaca-se que houve aumento do número de matrículas de alunos com deficiência nas escolas indígenas sem atendimento. Apesar de garantido legalmente o atendimento educacional especializado, observa-se que os alunos com deficiência que estudam em escolas indígenas não têm recebido real atenção do poder público.

Neste contexto, observa-se que a interface da Educação Especial com a Educação Escolar Indígena encontra-se fragilizada. Tomando como base o ano de 2010, verificou-se que os alunos com deficiência frequentam as escolas indígenas sem receber qualquer tipo de atendimento oferecido pela Educação Especial.

Cabe esclarecer que as análises, aqui apresentadas, tiveram intenção de demonstrar por meio dos dados estatísticos produzidos no âmbito do próprio Estado, um conjunto de reflexóes que possam contribuir tanto para elaboração e implementação de políticas quanto para colaborar com estudos que procurem analisar esses dados.

\section{Referências}

BRASIL. Constituição. Constituição da República Federativa do Brasil. Brasília: Senado, 1999.

Lei n. 9.394, de 20 de dezembro de 1996. Estabelece as diretrizes e bases da educaçáo nacional. Diário Oficial da República Federativa do Brasil, Brasília, DF, n. 248, 23 de dez. 1996.

Lei n. 4.024/1961. Dispóe sobre Lei de Diretrizes e Bases da Educação Nacional. Brasília, DF. Disponível em: <http://www.planalto.gov.br/ccivil_03/Leis/L4024.htm>. Acesso em: 22 abr. 2011.

Lei n. 5.692/71. Dispóe sobre Lei de Diretrizes e Bases da Educaçáo Nacional. Brasília, DF. Disponível em: <http://www.planalto.gov.br/ccivil_03/Leis/L5692.htm> . Acesso em: 22 abr. 2011.

Portaria n. 948, de 09 de outubro de 2007. Dispóe sobre Política Nacional de Educação Especial na Perspectiva da Educaçáo Inclusiva. Brasília, DF, 2008.

Declaraçáo de Salamanca e linha de açáo sobre necessidades educacionais especiais. Tradução: Edílson Alkmim da Cunha. 2. ed. - Brasília: CORDE, 1997.

Decreto 6949, de 25 de agosto de 2009. Disponível em: <http://www.planalto.gov.br/ccivil_03/_ Ato2007-2010/2009/Decreto/D6949.htm>. Acesso em: 01 out 2011.

Ministério da Educação. Instituto Nacional de Estudos e Pesquisas Educacionais. Microdados do censo escolar 2007. Brasília: MEC/INEP, 2007. 
BRASIL. Ministério da Educação. Instituto Nacional de Estudos e Pesquisa Educacionais. Microdados do censo escolar 2008. Brasília: MEC/INEP, 2008.

Ministério da Educação. Instituto Nacional de Estudos e Pesquisas Educacionais. Microdados do censo escolar 2009. Brasília: MEC/INEP, 2009.

Ministério da Educação. Instituto Nacional de Estudos e Pesquisas Educacionais. Microdados do censo escolar 2010. Brasília: MEC/INEP, 2010.

CONFERÊNCIA Mundial de Educaçâo para Todos. Declaração mundial sobre educaçáo para todos. Jomtien: UNESCO, 1990.

GATTI, B. A. Estudos quantitativos em educação. Educação e pesquisa, São Paulo, v. 30, p.11-30, 2004.

MAZZOTTA, J. S. Educação Especial no Brasil: história e políticas públicas. 5. ed. São Paulo: Cortez, 2005. $208 \mathrm{f}$.

MELETTI, S. M. F. BUENO, J. G. S. Escolarização de alunos com deficiência: Uma análise dos indicadores sociais no Brasil (1997-2006). In: Encontro Interinstitucional de Pesquisa: Políticas públicas e escolarização de alunos com deficiência. 2010, Londrina. Anais Encontro Interinstitucional de Pesquisa. Londrina, 2010. p. 01-18.

MINAYO, M. C.; SANCHES, O. Quantitativo-Qualitativo: oposição ou complementaridade? Caderno de Saúde Pública, Rio de Janeiro, p. 239-262, n. 9, v. 3, 1993.

PLETSCH, M. D.; FONTES, R. S.; GLAT, R. O papel da Educação Especial no processo de inclusão escolar: A experiência da rede municipal de educação do Rio de Janeiro. In: 29a Reuniáo Anual da Anped - Educação, Cultura e conhecimento na contemporaneidade - desafios e compromissos. 29, 2006, Caxambu. Anais 29a Reuniâo Anual da ANPED. Caxambu: ANPED, 2006.

SÁ, M. A. O escolar indígena com deficiência visual na Regiáo da Grande Dourados, MS: um estudo sobre a efetivação do direito à educação. 135 f. Dourados, 2011. Dissertação (Mestrado em Educação). Universidade Federal da Grande Dourados, 2011.

SOUZA, V. P. S. Crianças indígenas Kaiowá e Guarani: um estudo sobre as representaçōes sociais da deficiência e o acesso às políticas de saúde e educação em aldeias da região da Grande Dourados. 155f. Dourados, 2011. Dissertação (Mestrado em Educação). Universidade Federal da Grande Dourados, 2011.

VELTRONE, A. A. Inclusão escolar do deficiente intelectual no estado de São Paulo: Quem é este aluno e como é identificado. 2011. Sáo Carlos, 2011. Tese (Doutorado em Educação Especial - Educação do Indivíduo Especial). Universidade Federal de São Carlos, 2011.

\section{Correspondência}

Michele Aparecida de Sá - Rua Rafael Abreu Sampaio Vidal, no 2729, apto 11, Vila Costa do Sol, CEP: 13566-220, São Carlos - São Paulo, Brasil.

E-mail: micheledesa20@hotmail.com

Recebido em 03 de fevereiro de 2014

Aprovado em 07 de novembro de 2014 